\title{
"É BEM RARO ENCONTRAR ALUNOS VIOLENTOS ENTRE AQUELES QUE ACHAM SENTIDO E PRAZER NA ESCOLA": A VIOLÊNCIA ESCOLAR ENTRE DISCURSOS E CONCEITOS ${ }^{1}$
}

\author{
IT IS VERY RARE TO FIND VIOLENT STUDENTS AMONG THOSE WHO FIND MEANING \\ AND PLEASURE IN SCHOOL”: SCHOOL VIOLENCE BETWEEN DISCOURSES \\ AND CONCEPTS
}

\begin{abstract}
“ES MUY RARO ENCONTRAR A ESTUDIANTES VIOLENTOS ENTRE LOS QUE ENCUENTRAN SIGNIFICADO Y PLACER EN LA ESCUELA”: LA VIOLENCIA ESCOLAR ENTRE LOS DISCURSOS Y LOS CONCEPTOS
\end{abstract}

Monique Marques Longo ${ }^{1}$

${ }^{1}$ Doutora em Educação pela PUC/RJ. Docente da Universidade do Estado do Rio de Janeiro (UERJ) -Rio de Janeiro - RJ - Brasil.

Resumo: Ante a abrangência semântica que o termo violência escolar tem alcançado na atualidade, significá-lo rigorosamente torna-se imperioso se se pretende enfrentar o problema à margem da "histeria midiática" (DEBARBIEUX, 2002) ou da negação deste fenômeno que tem desestabilizado as múltiplas concepções de ensino e aprendizagem. Nesse sentido, este artigo se propõe a apreender como têm sido travadas as disputas que se pretendem significadoras das concepções e das práticas de enfrentamento das diversas facetas da violência que atravessam hoje o cotidiano das instituições de ensino. Trata-se de um estudo de natureza descritiva bibliográfica cujos principais aportes teóricos residem em Alice Itani, Miguel Arroyo, Bernard Charlot, Julio Aquino, Mirian Leite e Eric Debarbieux. Algumas considerações foram levantadas: (1) a indistinção conceitual dos termos utilizados para significar as muitas facetas da violência escolar pode torná-la categoria segregadora de um grupo rotulado como violento-infrator; (2) a falta de rigor apresentada por alguns autores ao discutir a temática retratam a fragilidade das categorias de público a qual a escola hoje busca representar, e de infância como algo universalmente reconhecível; e (3) a violência pode decorrer do hiato existente entre o aluno real que hoje se insere na escola e o ainda vigente modelo pedagógico moderno hegemonicamente determinado que desconsidera as diferenças identitárias. Ficou clara, por fim, a importância de se enfrentar a desestabilização provocada pela questão da violência, e que a prática de refletir semanticamente o termo constitui-se um primeiro passo à formulação de estratégias para o seu enfrentamento.

Palavras-chave: Violência em meio escolar; Abrangência semântica; Formação docente.

\begin{abstract}
Given the semantic comprehensiveness that the term school violence has today, defining it clearly becomes imperative if we want to deal with this problem that is now bordering on "media hysteria" (Debarbieux, 2002), or the denial of this phenomenon that has destabilized the multiple concepts of teaching and learning. This article seeks to understand how the disputes that are meant to signify the concepts and practices of dealing with the various facets of violence that today are part of the daily lives of educational institutions have been dealt with. This is a descriptive, bibliographic study, for the main theoretical contributions were from Alice Itani, Miguel Arroyo, Bernard Charlot,
\end{abstract}


Julio Aquino, Mirian Leite and Eric Debarbieux. Some considerations have been raised: (1) the conceptual lack of distinction of the terms used to define the many facets of violence in school settings can turn it into a category that segregates a group labeled as violent-offender; (2) the lack of rigor presented by some authors when discussing the theme demonstrates the fragility of the categories of public that the school today seeks to represent, and of childhood as something universally recognizable; and (3) violence may the result of the gap between the real child that arrives in school and the modern hegemonic pedagogical model that is practiced today, that fails to consider identify differences. Finally, the importance of facing the destabilization caused by the issue of violence was clear, and the practice of reflecting it semantically constitutes a first step in the formulation of strategies for dealing with it.

Keywords: Violence in schools; Semantic comprehension; Teacher training.

Resumen: Ante el alcance semántico a que el término violencia escolar ha llegado hoy en día, se hace imperioso darle un significado riguroso si se quiere abordar el problema al margen de la "histeria de los medios" (Debarbieux, 2002) o de la negación de este fenómeno que ha desestabilizado las múltiples concepciones de enseñanza y aprendizaje. En este sentido, este artículo tiene como objetivo comprender cómo han sido realizadas las disputas que pretenden ser significadoras de las concepciones y de las prácticas de enfrentamiento de las diversas facetas de la violencia que actualmente impregnan la vida cotidiana de las instituciones educativas. Se trata de un estudio descriptivo bibliográfico cuyas principales contribuciones teóricas residen en Alice Itani, Miguel Arroyo, Bernard Charlot, Julio Aquino, Mirian Leite y Eric Debarbieux. Se han planteado algunas consideraciones: (1) la indistinción conceptual de los términos utilizados para significar las múltiples facetas de la violencia escolar pueden convertirla en una categoría segregadora de un grupo denominado como grupo violento infractor; (2) la falta de rigor presentada por algunos autores al discutir el tema retratan la fragilidad de las categorías de públicos a los que la escuela busca representar hoy en día, y la infancia como algo universalmente reconocible; y (3) la violencia puede provenir de la brecha entre el alumno real que llega a la escuela hoy y el modelo pedagógico moderno hegemónicamente determinado, aún vigente, que no tiene en cuenta las diferencias identitarias. Se hace evidente, por último, la importancia de abordar la desestabilización causada por el tema de la violencia, y que la práctica de reflejar semánticamente el término constituye un primer paso en la formulación de estrategias para resolverlo.

Palabras clave: Violencia en el medio escolar; Alcance semántico; Formación docente.

\section{INTRODUÇÃO}

No último dia 30 de março, Maria Eduarda, aluna matriculada no sétimo ano da Escola Municipal Jornalista Daniel Piza, na zona norte do Rio de Janeiro, foi baleada durante uma aula de Educação Física. De acordo com a polícia militar, a adolescente foi atingida por um disparo de arma de fogo e não resistiu, após confronto entre bandidos e a PM, em Fazenda Botafogo, perto do Rio Acari.

No dia 7 de abril de 2011, Wellington Menezes de Oliveira, de 23 anos, atirou em 12 crianças que estavam dentro da Escola Municipal Tasso da Silveira, onde o próprio assassino havia cursado o Ensino Fundamental. Wellington deixou uma carta expondo estar se vingando dos episódios de bullying que sofrera como aluno na escola de Realengo.

Como estes, são muitos os episódios veiculados hoje pelos diversos meios de comunicação que retratam a violência presente nas diversas instituições de ensino. Tal fato 
fomenta um intenso debate entorno do fenômeno, realizado nos diversos âmbitos sociais, das mídias às universidades. Em todos, as tensões que se descortinam ao tentar enfrentar ou definir causas para o problema aumentam, sobretudo, ante à abrangência semântica com que o termo é, hoje, concebido e discursivamente significado.

Ambos os episódios descritos anteriormente assemelham-se? Ambas facetas da violência escolar são oriundas das mesmas causas? Todos os fenômenos que fogem ao controle do professor e da escola, das indisciplinas aos homicídios, são violências? Parte-se do pressuposto que "definir" a violência escolar é, antes, mostrar como ela é socialmente construída em sua própria designação; como é discursada, representada socialmente, a ponto de ser problematizada por uma comunidade epistêmica. Debarbieux (2001, p. 164) postula que "fatos sociais heterogêneos sejam reunidos sob o termo genérico de 'violência' pelos atores da escola é em si mesmo um fato social digno de ser pensado".

Ante a estas primeiras exposições, objetiva-se, neste artigo, apresentar tanto uma discussão teórica acerca das atuais disputas discursivas que se pretendem significadoras das diversas manifestações de violência que atravessam as instituições de ensino, assim como postular possíveis consequências às diversas concepções de ensino aprendizagem ao se discursar sobre o tema sem uma certa rigorosidade léxica e/ou semântica.

Trata-se de um estudo de natureza teórico e do tipo pesquisa bibliográfica no qual se utilizou como aporte teórico Miguel Arroyo (2007), Alice Itani (1998), Julio Aquino (1998), Éric Debarbieux (2001), Leite (2006), Vera Candau et al. (1999) e Bernard Charlot (2002). Esses autores se mostraram consistentes interlocutores na discussão aqui proposta.

Objetiva-se, por fim e de forma geral, oferecer um mapeamento relevante para se compreender como as várias facetas da(s) violência(s) em meio escolar têm sido discursadas nas pesquisas acadêmicas realizadas sobre a temática. Acredita-se ser este um primeiro passo para se construir estratégias de enfrentamento deste fenômeno que tem desestabilizado, no cenário contemporâneo, as diversas concepções de ensino e aprendizagem.

\section{VIOLÊNCIA(S) OU VIOLÊNCIA ESCOLAR: UM DEBATE SEMÂNTICO?}

São múltiplas as tensões que norteiam os embates que se pretendem significadores da(s) violência(s) que adentram as instituições de ensino na atualidade. Professores têm suas concepções didáticas e práticas desestabilizadas quando interrompem planejamentos pedagógicos por indisciplina por parte dos alunos, culpando a atual cultura juvenil como causa do não cumprimento dos seus currículos. Estes mesmos professores parecem conceituar tais indisciplinas, assim como os conflitos psíquicos e físicos, indistintamente, como violência escolar.

Ao se analisar a literatura direcionada ao tema, evidenciou-se, no entanto, que a abrangência semântica que abarca a questão não desafia apenas professores. Autores diversos nomeiam, muitas vezes, indisciplinas, conflitos, agressões, agressividades como violências. A falta de consenso, ou o mínimo rigor conceitual, não apenas dificulta o diálogo, mas possibilita 
que o termo seja utilizado como categoria segregadora de alunos que não se enquadram nos ideais legitimados pelas instituições educacionais.

Em seu artigo A violência na escola: como os sociólogos franceses abordam essa questão, Bernard Charlot (2002, p. 434) postula que o aumento da angústia social ante à violência escolar leva "a discursos sociomidiáticos que têm a tendência de amalgamar fenômenos de natureza muito diferente". Tal fato exige, ainda para o autor francês, que os pesquisadores da ciência da educação saibam "falar com rigor desta noção de violência que compreende coisas muito diferentes" (CHARLOT, 2002, p. 432).

Defendendo a ideia de que a violência não é um fenômeno inédito e nem contemporâneo, mas inerente à escola como instituição escolar desde seus primórdios, Charlot (2002) ainda advoga ser a angústia social diante da violência escolar o que aumentou nos últimos anos, fato corroborado pelo excesso da sua midiatização. A vigência de formas de violência muito mais graves, protagonizadas por alunos cada vez mais jovens, o aumento do número de "instruções externas" na escola e o medo de que essas ameaças aconteçam todos os dias, fomentam certa angústia social face à violência, tema interessante a ser midiatizado por veículos de comunicação cada vez mais velozes.

Corroborando pressupostos de Bernard Charlot, Debarbieux (2006, p. 23) aprofunda a hipótese e afirma que a violência escolar é mais um tema que comporta um alto grau de manipulação. O exagero midiático, as estratégias reparadoras promulgadas pelos agentes públicos e o emergente mercado de segurança nas escolas são discursos que uma vez acionados produzem e/ou reforçam uma "histeria da violência". Podemos até definir, segundo ainda Debarbieux (2006), a data de início do fenômeno: 12 de novembro de 1990.

Neste dia, sob a famosa Ponte das Almas em Paris, trinta e cinco mil estudantes dos lycées agrediram policiais com projéteis e quebraram vitrines de lojas sob os holofotes de jornalistas. Concomitante, os alunos levantavam faixas exigindo mais segurança e autoridade nas escolas. Tal fato foi midiatizado com sarcasmo por toda a rede de comunicação mundial. Desde então, assegura Debarbieux (2006, p. 14), a mídia francesa e, posteriormente, a mundial, descobriu um fenômeno que não mais abandonou e que passou a ditar, de certa forma, o ritmo das agendas políticas em educação.

Debarbieux (2006) ressalta que, na França, a violência na escola já se tornara problema a ser investigado por Crubellier (1979), Caron (1999), Testanière (1967), Bourdieu e Passeron (1970). Até 1991, entretanto, não havia sido tomada nenhuma medida concreta, administrativa e/ou política sobre o tema. Posteriormente ao episódio ocorrido na Ponte das Almas, a violência escolar tornou-se uma questão ideológica, assunto de pautas econômicas e sociais em um momento privilegiado à extrema-direita francesa.

Podemos ratificar que a vigência da violência escolar como tema obrigatório de agendas políticas não ficou limitada à França. Segundo pesquisas publicadas pelo Laboratório Internacional de Violência Escolar², posteriormente à revolta dos alunos franceses, na Suécia, Holanda, Espanha e Alemanha, foram implementados programas de ações preventivas da violência nas diversas instituições educacionais. Na Inglaterra, foi promulgada a obrigação de efetivar, em todas as escolas, programas de prevenção ao bullying. No Japão, a luta é contra 
a opressão escolar do "Ijimé" ${ }^{3}$ Na Índia, a violência tornou-se desculpas para castigos físicos, os quais também preenchem as páginas dos jornais. Nos EUA, dentre outras situações, a violência virou manchete de noticiários e roteiro de filme - como em Bowling for Colombine assistido por expectadores de todo o mundo (LONGO, 2014, p. 15).

Desta forma, estamos expostos a uma série de discursos políticos, programas oficiais e/ ou filmes formulados sob a exacerbação de fatos trágicos que focalizam cenas espetaculares e sangrentas, tendo a escola como um cenário antes inimaginável. Tais acontecimentos são raros, no entanto, se compararmos à violência presente em outros espaços sociais. Desde 1960, afirma Debarbieux (2012), contamos no máximo trinta registros de grandes episódios desta natureza, em todo o mundo, ocorridos especificamente dentro de escolas.

Segundo o relatório do National School Crime and Safety Survey, apresentado por Debarbieux (2006, p. 25), "desde 1992 os jovens com idades compreendidas entre 15 e 19 anos correram em média cerca de 70 vezes menos riscos de serem assassinados na escola (ou a caminho da escola) do que em outras circunstâncias". O mesmo relatório afirma que, de 1992 a 2000, houve 234 homicídios nas escolas americanas entre jovens de 15 a 19 anos. Considerando que o número de jovens desta faixa etária nos campi escolares é de cerca de 50 milhões, o risco de ser morto nas escolas é de menos de um em um milhão por ano. Em contrapartida, fora da escola, foram mortos 24.406 jovens desta faixa etária. O próprio FBI recusa proceder de forma diversa com alunos cujos perfis demonstram tendência a comportamentos violentos, argumentando que a raridade dos fatos não justifica a estigmatização da população escolar.

A despeito do impacto provocado no imaginário social, a "histeria midiática" das grandes violências traz consequências à solução real do problema. Ela nos faz desconfiar da legitimidade dos números anunciados, falseia suas causas e impossibilita seu entendimento quando obscurece fatores que provocam o fenômeno e inviabilizam os processos de ensino e aprendizagem. Por outro lado, não podemos cair numa postura de resistência ao problema que, sem dúvidas, afeta o cotidiano das escolas e cujas causas são, segundo Candau, Nascimento e Lucinda (1999), multidimensionais. Trabalhar, portanto, entre o apelo da mídia e a negação de um fenômeno com graves consequências para o processo de ensino-aprendizagem é o desafio que nos é colocado. Cabe-nos, nós pesquisadores do tema, focarmos nosso olhar para as possibilidades que a própria escola tem de solucionar o problema e, sobretudo, as responsabilidades quanto às suas causas.

Buscando compreender a origem da questão, Alice Itani argumenta no seu artigo $A$ violência no imaginário dos agentes educacionais (1998) que a violência faz parte da escola desde a sua formação como instituição social, estando presente no cotidiano dos alunos e dos professores de forma visível, mas, sobretudo, invisivelmente. A despeito de muitas vezes supormos ser os atos de violência sempre advindos de agentes externos, para a professora da UNESP, a violência mais feroz se presentifica dentro das nossas escolas de forma invisível. Por meio dos processos de formação, ideologização e pelas práticas educativas que se fomentam e perpetuam formas de violência mais danosas ao aluno e à democratização social: a violência simbólica. 
Essa violência invisível se realiza ao longo de todo o processo educativo. Para Itani (1998), inicia-se pela classificação dos indivíduos e grupos sociais em faixas etárias, níveis de inteligência, sexo, cor, raça, dividindo-os em normais e anormais, bons ou maus alunos, capazes ou não. Aqueles que não se adéquam aos padrões predefinidos de inteligentes são estigmatizados, e as condições de aprendizagem passam a ser a eles limitadas: vagas em outras escolas, conteúdos simplificados e/ou não abordados, classes de alunos "indisciplinados", etc. Desta forma, perpetuam-se as condições sociais por meio das condições educacionais, como já acusavam Bourdieu e Passeron (1975).

Já para Charlot (2002), a violência simbólica se resumiria em apenas uma das facetas possíveis de violência que norteiam as instituições de ensino. Para melhor entendimento, propõe uma classificação e defende ser relevante a distinção entre os termos violência na escola, violência à escola e violência da escola. A violência institucional que os próprios alunos suportam por meio da maneira como a escola os disciplinalizam - e conceituada por Itani como violência simbólica -, para Charlot (2002) é uma típica violência da escola. Já a violência na escola é aquela que acontece dentro da instituição, porém provocada por agentes externos, como a entrada de gangues na escola para brigar com um aluno. Esta manifestação é diferente, por sua vez, da violência à escola, caracterizada por depredações do espaço escolar ou dos agentes que a ele pertence como professores ou coordenadores pedagógicos. Esta distinção é necessária, para Charlot (2002), quando compreendemos ser, a escola, largamente impotente à violência na escola, mas que dispõe de certa margem de ação ante a violência à escola e da escola.

Para o professor da Université Paris 8, alguns pesquisadores franceses têm desenvolvido, ainda, uma distinção muito útil do ponto de vista teórico e prático acerca dos termos agressão, agressividade, transgressão, incivilidade e do termo violência. A agressividade seria uma disposição biopsíquica reacional à frustração, normal, portanto, em todos os seres humanos. A agressão é um ato de brutalidade física ou verbal, porém sem utilização da força muito além do que é exigido pelo resultado, ou movido por uma forma de obter prazer de causar mal, de destruir - características, estas, da violência. O comportamento contrário ao regulamento interno do estabelecimento caracteriza a transgressão, quando não é ilegal do ponto de vista das leis. $E$ a incivilidade não contradiz nem as leis e nem as normas institucionais, mas apenas as regras de boa convivência; como exemplo temos os empurrões, as grosserias e os pequenos ataques ao professor.

No entanto, para Charlot, muitas destas distinções estão ultrapassadas quando observamos um continum de violência na escola. O que era apenas uma incivilidade destrói tão mais profundamente a identidade de um professor do que uma agressão física, característica de uma violência; ou o que era uma violência se mostra tão "natural" e insignificante ante tantos outros atos mais agressivos. E resume: "é difícil falar da violência sem fixar normas. Mas parece impossível falar dela rigorosamente, fixando normas" (CHARLOT, 2002, p. 439).

O que podemos observar como convergência entre os autores brasileiros, ante tal dificuldade, é uma despreocupação em distinguir tais atos, embora todos ressaltem a importância de se definir o termo de forma rigorosa. Em Itani (1998), apenas há uma 
classificação entre violência visível - materializada pelas modificações estruturais por meio da construção de muros, grades, câmeras de vídeos - e a invisível, generalizada pela autora como violência simbólica.

Para Julio Aquino (1998), ambas facetas se assemelham e retratam um único fenômeno. "A indisciplina nossa de cada dia, a turbulência ou apatia nas relações, os confrontos velados, as ameaças de diferentes tipos, os muros, as grades e a exclusão", são todos "efeitos concretos" da violência na escola (AQUINO,1998, p.7). A problematização feita é em relação às metodologias que visam compreendê-las.

O professor da Faculdade de Educação da USP busca contrapor uma leitura de cunho institucional da violência escolar às abordagens sociologizantes e/ou psicologizantes do fenômeno. Em ambas as correntes, a violência portaria uma raiz essencialmente exógena em relação à prática institucional escolar. De acordo com a perspectiva clínico-psicologizante, que se aporta em ideias como a "desestruturação da personalidade" ou "déficit em alguma fase do desenvolvimento", cremos na estruturação psíquica prévia dos personagens envolvidos em determinado conflito. Já numa perspectiva sociologizante, acusamos as coordenadas políticas, econômicas e culturais ditadas pelo momento histórico vigente. Em contraposição, Aquino defende o pressuposto de residir, a raiz da violência, na relação professor-aluno, a qual não pode prescindir de certo grau de violência positiva, circunscrita na necessária autoridade docente.

Este posicionamento do professor da USP é justamente o que Debarbieux questiona em suas pesquisas. O professor da Université de Bourdeaux II, em seu artigo intitulado $A$ violência na escola francesa: 30 anos de construção social de um objeto (1967-1997), explicita que o termo violência escolar na França permanece à espera de uma definição precisa. $\mathrm{O}$ autor denuncia uma visão inflacionista da violência, quando sobre tal conceito se agrupam tanto agressões físicas, vandalismos e mortes, quanto atos típicos de incivilidades, como insultos, interpelações e humilhações. E conclui que "uma tão grande extensão tornaria o conceito impensável, por confusão léxica e semântica" (DEBARDIEUX, 2001, p. 163).

No entanto, Debardieux rechaça qualquer busca essencialista de se definir o termo, mas apresenta o caminho percorrido pela construção do objeto violência escolar na desconstrução/ construção da emergência social do fenômeno. É no caráter contingente, circunscrito a um contexto específico - histórico e social - que cremos assentar sua "definição". O trabalho do pesquisador consiste apenas em problematizar essas categorizações e as condições sóciohistóricas sob as quais emergiu tal fenômeno social; algo inimaginável, parece, para Aquino (1998), já que, para o professor brasileiro, a violência tem sim uma "raiz fixa".

Ao apresentar de forma profunda o caminho percorrido pelos sociólogos na busca por construir a violência escolar como objeto de análise, Debardieux (2001) expõe que as premissas de uma sociologia da violência escolar foram postuladas por Durkhein. O sociólogo coloca em evidência, pela primeira vez, a imprescindibilidade da disciplina escolar para a construção de uma personalidade social, considerando ser a violência uma resistência à opressão sofrida pelas instituições. No entanto, é Testanière (1967) quem apresenta, segundo Debardieux, dados empíricos que retratam novas representações da violência como sintomas da fragilidade da escola democrática. 
"A chegada de novos públicos, até então à margem do segundo grau, produzia novas formas de desordem: a bagunça anômica. As dificuldades de manutenção da coesão social tiveram como consequência (...) a bagunça tradicional", expõe Debardieux (2001, p. 165). São essas mesmas as representações compartilhas por Charlot no fim de seu artigo publicado na Revista Sociologias, em 2002 e de Miguel Arroyo em Quando a violência infanto-juvenil indaga a pedagogia, de 2007.

Após o seu esforço de definição do termo, Charlot sugere ser a não entrada do aluno popular na lógica das instituições escolares fundadas num ideal de aluno protótipo da classe média, "a fonte de revolta (...) e de uma tensão que leva a incidentes violentos" (CHARLOT, 2002, p 441). Sob o aporte de dados empíricos por ele apresentados, este aluno sente-se passivo no processo de ensino e aprendizagem. A escola não tem sentido para o aluno. A lógica institucional ainda é regida pelos professores que escolhem previamente os conteúdos abordados, os quais são únicos ativos no processo. E Charlot (2002, p. 442) conclui: "é bem raro encontrar aluno violentos entre os que acham sentido e prazer na escola".

Ao visar apreender as causas das dispersões dos alunos durante as aulas, Miriam Leite (2006) traz algumas pistas quanto às suas características, distinguindo-as das demais violências. Distinta dos conflitos que produzem consequências físicas ou psíquicas àqueles que nelas se envolvem, a dispersão escolar pode ser nomeada quando há uma distração por parte do aluno, isto é, quando eles não se sentem motivados a participarem das atividades propostas.

As conversas paralelas entre alunos durante a fala docente, jogar bolinha de papel no colega, pequenas brincadeiras não repetitivas, mas esporádicas entre as crianças, não são tão graves como as violências escolares, mas, segundo Leite (2006), podem dificultar ou mesmo inviabilizar os processos de ensino e aprendizagem. Tais ocorrências devem ser tratadas de forma diferente das grandes violências ou do bullying - as quais multas vezes exigem a intervenção de agentes externos na escola. As dispersões, segundo ainda a autora, devem ser pensadas segundo estratégias didáticas que incitem o aluno a participar e se inserir nas propostas pedagógicas.

Sob a base dos pressupostos formulados por Candau (2002a, 2002b,2006) para se pensar a escola no mundo atual, Miriam Leite (2006) nos incita a pensar tanto a importância de considerarmos a multidimensionalidade da prática didática, como as implicações que a incorporação de uma perspectiva intercultural nos processos de ensino e aprendizagem trazem para pensar a escola em termos de diferença cultural (CANDAU; LEITE 2006).

Repensar nossas práticas pedagógicas na sua multidimensionalidade e em interlocução com uma perspectiva intercultural nos permite afirmar que o aumento da dispersão, ou mesmo das muitas facetas da violência escolar, tem demonstrado a fragilidade das categorias utilizadas tradicionalmente como aporte para pensar os atores e os fazeres educativos. Os ideais tradicionais de aluno, professor, conteúdos e métodos pedagógicos mostram-se insuficientes. Hoje, buscamos abarcar tanto as diferenças constituintes dos atores escolares, como a diversidade dos meios de se aprender - compreendidos nas suas dimensões técnicas, mas, também, afetiva e sociopolíticas (CANDAU, 2002a). Desnaturalizar, desconstruir e reconstruir estas categorias acionadas no decorrer dos debates didáticos, portanto, mostram-se como a 
única saída para chamar novamente o aluno para inserir-se no processo educativo de forma significativa e prazerosa. Desta forma, podemos pensar não apenas na diminuição da dispersão, mas principalmente numa escola eficaz quanto à aprendizagem integral do seu aluno.

Miguel Arroyo, em 2007, não apresenta um posicionamento diferente de Leite (2006), Debarbieux (2001) ou Charlot (2001) quanto à necessidade da distinção do termo e das diferenças entre dispersão, agressividade, bullying e outras manifestações violentas. No entanto, vai além e defende que essa indistinção faz com que o termo se torne uma categoria classificatória, segregadora das condutas de um determinado coletivo e/ou crianças. Arroyo expõe:

...o conjunto de condutas indisciplinadas que sempre aconteceram nas escolas passou a ser interpretado e classificado como violências, elevando a diversidade de condutas desviantes a essa condição e segregando os alunos tidos como indisciplinados na categoria mais temida, segregadora e estigmatizante de violentos. (ARROYO, 2007,p. 789).

Segundo Arroyo, a cultura escolar opera tradicionalmente com parâmetros classificatórios dos educandos. A introdução da categoria alunos violentos produz um novo parâmetro que toca na dimensão humana mais segregadora, com impactos não apenas nos processos de avaliação, ensino, socialização do aluno, mas nos seus processos de desenvolvimento: psíquico, identitário e ético. As consequências para a criança, ao ser taxada como menor infrator/violento, são inúmeras e, às vezes, irreversíveis.

Para segregar deve-se, sobretudo, compartilhar de um ideal de normal, de aluno padrão, de capacidade. O problema levantado pelos cinco autores é que esse ideal de aluno, de criança e jovem circunscrito no imaginário das instituições educacionais não convém com o aluno real que chega à escola hoje. O que acontece, advoga Arroyo (2007, p 795), é que "todo conceito generalista tende a ignorar as formas concretas, diversas, de vivência da cidadania e ignorar os diferentes contextos de desigualdade social e diversidade cultural". A violência seria apenas um "sintoma" deste hiato, sugerimos assim concluir a leitura destes cinco autores.

"É fácil constatar que os embates sobre as violências apontam para sujeitos concretos: crianças, adolescentes e jovens populares" (ARROYO, 2007, p. 798). Os "catalogados" como menores infratores são, em sua maioria, populares, pobres, negros; longe dos ideais fundados em parâmetros eurocêntricos de crianças quietas, brancas, heterossexuais. E quando a violência acontece, apenas retrata a fragilidade da escola como espaço público; e da criança como cidadã (o que é ser cidadã?) e de direitos (quais?).

A afirmação da educação como direito de todo cidadão, bandeira dos anos de 1980, e o reconhecimento da criança como sujeito de direitos como exposto no Estatuto da Infância e da Adolescência, bandeira dos anos 90, para Arroyo, foram dois fatos relevantes que contribuíram com a difusão das representações de escola como tempo-espaço público e, da criança, como cidadã de direito. O problema é que as concepções institucionalmente legitimadas de direito e de cidadania são colocadas num plano tão abstrato que não são capazes de incorporar cidadãos concretos, infâncias reais, contextualizadas.

A violência infanto-juvenil na sociedade e nas escolas, entretanto, apenas evidencia a fragilidade do trato desses campos, principalmente quando observamos alunos sendo expulsos da sala ou da escola por não se adaptarem à lógica dos professores, segundo parâmetros que 
não correspondem ao real. Estas crianças não apenas são segregadas, estereotipadas, mas destituídas de usufruir destes supostos "direitos" de estudar e ser criança. Arroyo, por fim, defende a urgência de mais pesquisas que desnaturalizem e ressignifiquem a escola como espaço público - que atenda a todos de forma homogênea - e das infâncias como cidadãos de direitos - e que sejam compreendidas em sua diversidade.

\section{Algumas CONSIDERAÇõES FINAIS}

Relembramos que o objetivo do artigo aqui proposto residiu em apresentar algumas tensões que se descortinam durante os embates que se pretendem significadores das violências que hoje atravessam as instituições de ensino. Observamos que não são apenas os professores que se sentem inseguros ao nomear facetas diversas da violência que ocorrem no seu cotidiano. Mas pesquisadores da temática são também desafiados pela abrangência semântica que o termo hoje abarca.

A distinção do conceito, de forma rigorosa, traz implicações tanto aos embates acadêmicos quanto aos novos fazeres e saberes pedagógicos. Tais definições e implicações foram aqui levantadas, assim como expusemos algumas consequências do uso indistinto do termo violência escolar. Rotular uma criança como violenta quando apenas se apresenta dispersa por não se adaptar ao ideais de aluno impostos por parâmetros modernos de escola apresentou-se como uma delas. Parece ser esta sim, uma violência, porém produzida pelas próprias instituições educacionais aos alunos desconsiderados nas suas diferenças. Fato já anunciado por Bourdeu e Passeron (1975) e aqui revisto por Itani (1998).

Sob o aporte teórico de Miguel Arroyo, Alice Itani, Julio Aquino, Éric Debarbieux, Mirian Leite e de Bernard Charlot, apresentamos as distinções dos termos violência na escola, da escola e à escola, assim como entre violência simbólica e a visível. Posteriormente, distinguimoso conceito violência dos termos agressão, agressividade e da dispersão, deixando clara a fluidez que tais conceituações apresentam. Ressaltamos, ainda, as possibilidades de a violência refletir um hiato entre os alunos reais que chegam hoje à escola com suas diferenças de cor, raça, etnia, gênero, orientação sexual e outros marcadores identitários e os protótipos modernos de aluno padrão homogêneo produzidos segundo uma lógica etnocentricamente determinada. O conceito violento-infrator é reeditado como categoria segregadora e classificatória de alunos que apenas não se encaixam nos padrões ideais de criança e juventude universalmente legitimados pelos sistemas e pelas práticas educacionais. Tal fato faz urgir uma reflexão sobre parâmetros vigentes de escola, aluno, criança e dos processos de ensino e aprendizagem adotados.

Ressaltamos, por fim, que o acolhimento das diferenças constituintes dos alunos reais que chegam hoje à escola - cujo tempo-espaço se pretende democrático - mostrou-se possível estratégia subversora, ou, ao menos, amenizadora das diversas facetas do fenômeno da violência que hoje desestabiliza concepções de alunos, função docente, escola como espaço público e educação como direito de todo cidadão. 
ARROYO, M. Quando a violência infanto-juvenil indaga a pedagogia. Revista Educação e Sociedade, 28, n.100, p. 787-807, 2007.

AQUINO, J. A violência escolar e a crise de autoridade docente. Caderno Cedes, n 47, 19, p. 7-19, 1998.

BOURDIEU, P.; PASSERON, J. C. A reprodução: elementos para uma teoria do sistema de ensino. Rio de Janeiro: Francisco Alves, 1975.

CANDAU, V. M. F. Sociedade, Educação e Cultura(s): questões e propostas. Petropolis: Vozes, 2002a.

CANDAU, V. M. F. Didática em questão. Petropolis: Vozes, 2002b.

CANDAU, V. M., LEITE, M. S. Educação Intercultural e cotidiano escolar. Rio de Janeiro: 7letras, 2006. CANDAU, V. M.; LUCINDA, M. C.; NASCIMENTO, M. G. Escola e violência. Rio de Janeiro: DP \& A, 1999. CHARLOT, B. A violência na escola: como os sociólogos franceses abordam essa questão. Sociologias, n 8, ano 4, p.8-16, 2002.

DEBARBIEUX, E. A violência na escola francesa: 30 anos de construção de um objeto (1967 -1997). Educação e Pesquisa, vol. 27, n 1, 2001.

DEBARBIEUX, E. Violência na escola: um desafio mundial? Paris: Instituto Piaget, 2002.

DEBARBIEUX, E. Violência na escola. Paris: Instituto Piaget, 2006.

DEBARBIEUX, E. Eric Debarbieux fala sobre o bullying. In: Revista Abril, 2012, http://revistaescola.abril. com.br/gestao-escolar/eric-debarbieux-fala-combate-ao-bullying-669588.shtml. Acessado em: 19/06/21012.

ITANI, A. A violência no imaginário dos agentes educativos. Caderno Cedes, 47, 19, p. 36-50,1998.

LEITE. M. Dispersão na sala de aula: "Esse barulho é e dentro ou vem de fora?". Anais da ANPED, Caxambu, 2006.

LONGO, M. M. "Professora, fala alguma coisa boa da educação pra gente por favor!": violência, assertividade e pressupostos arendthianos na formação docente. Tese apresentada ao programa de pós-graduação em educação da PUC-Rio. Rio de Janeiro, 2014.

Artigo recebido em: 11/04/2017

Aprovado em: 25/07/2017

\section{CONTATO PARA CORRESPONDÊNCIA:}

Monique Marques Longo. E-mail: moniqueml@globo.com

NOTAS

1 Artigo baseado na pesquisa apresentada no Congresso Internacional Cotidianos Diálogos sobre Diálogos

20 Laboratório Internacional de Violência Escolar, dirigido por Eric Debarbieux com sede em Paris, é um dos centros de combate à violência escolar e parte de uma das ações da UNESCO pela paz. 
3 O Ijimé é uma prática de bullyng típica da cultura japonesa. A prática, muitas vezes defendida e considerada parte da tradição por alguns japoneses, não se restringe ao ambiente escolar, mas é visivel entre adultos. O preconceito entre adultos acaba por reverberar e ratificar o agir violento entre os jovens e as crianças. 